\title{
Field Oriented Control of PMSM Supplied By Photovoltaic Source
}

\author{
Mehimmedetsi Boujemaa, Chenni Rachid
}

Electrotechnical Department, Mentouri University, Constantine, Algeria,

\begin{tabular}{l} 
Article Info \\
\hline Article history: \\
Received Oct 12, 2015 \\
Revised Dec 14, 2015 \\
Accepted Jan 2, 2016 \\
\hline
\end{tabular}

\section{Keyword:}

Field oriented control Permanent magnet synchronous machines

Photovoltaic

The inverter

\begin{abstract}
The Permanent magnet synchronous motor (PMSM) is suitable for many applications, such as traction, aeronautics and generally in industrial automated processes. In our work, we will study the application of PMSM in renewable energies especially in solar pumping. Our objective is to model the complete system, including the photovoltaic inverter, PMSM and the centrifugal pump under Matlab/Simulink environment. Solar panels generate electrical energy as direct current by direct conversion of solar radiation using semiconductor materials made of monocrystalline, polycrystalline or amorphous silicon. The energy received depends on radiation and on ambient temperature. The permanent magnet synchronous motor (PMSM) is not stable in open loop. To control the PMSM in terms of speed, torque or position, we need to implement vector control. We will establish the field oriented control of a PMSM supplied by a photovoltaic source with a focus on their applications in variable speed domain.
\end{abstract}

Copyright $\left({ }^{\circ} 2016\right.$ Institute of Advanced Engineering and Science. All rights reserved.

\section{Corresponding Author:}

Mehimmedetsi Boujemaa, Electrotechnical Department, University of Mentouri Brothers, Constantine 1, Constantine, Algeria.

Email: monir_ifp@yahoo.fr

\section{INTRODUCTION}

The permanent magnet synchronous motor (PMSM) has three phases winding on stator represented by the three axes $(a, b, c)$ phase-shifted of $120^{\circ}$ with respect to each other (Figure 1) and has permanent magnets in the rotor ensuring its excitation. Depending on how the magnets are placed, we can distinguish two types of rotors; in the first type, magnets are mounted on the surface of the rotor with a homogeneous air gap, the motor is called "smooth air gap PMSM" and inductors are independent on the rotor position. In the second type, magnets are mounted inside the rotor mass and the air gap will vary because of the salience effect. In this case, inductors are highly dependent on the rotor position. Synchronous motors have a remarkable feature; the speed is constant regardless of the load.

The field oriented control (foc) is used for many years. It implements Park transformation which shows, like a separately excited dc machine, the expression of the instantaneous torque as a product of magnetic flux and current. In addition, there is the possibility to reduce the oscillations for a desired torque, to save energy delivered, to reduce the current harmonics and to improve power factor. When the motor model used is correct, the foc works well. [1],[2]. 


\section{DYNAMIC MODEL OF A SYNCHRONOUS MOTOR}

\subsection{Mathematical Model of the Permanent Magnet Synchronous Motor (PMSM)}

The dynamic model of a permanent magnet synchronous motor with rotor reference frame can be described by the equations below, considering the conditions of non-saturation of the magnetic circuit and the magnetomotive force MMF is a sinusoidal distribution created by the stator windings.

$$
\begin{aligned}
& {\left[V_{a b c}\right]=[R]\left[i_{a b c}\right]+\frac{d\left[\Phi_{a b c}\right]}{d t}} \\
& {\left[\Phi_{a b c}\right]=\left[\begin{array}{c}
\Phi_{a} \\
\Phi_{b} \\
\Phi_{c}
\end{array}\right] ;[R]=\left[\begin{array}{lll}
R & 0 & 0 \\
0 & R & 0 \\
0 & 0 & R
\end{array}\right] ;}
\end{aligned}\left[\begin{array}{c}
\left.i_{a b c}\right]=\left[\begin{array}{c}
i_{a} \\
i_{b} \\
i_{c}
\end{array}\right] ;\left[V_{a b c}\right]=\left[\begin{array}{c}
V_{a} \\
V_{b} \\
V_{c}
\end{array}\right] ;
\end{array}\right.
$$

With $V_{a b c}, i_{a b c}$ and $\Phi_{a b c}$, representing respectively the voltages, the currents and the total flux of stator phases. $R$ indicates the resistance of a stator phase.

Total fluxes are expressed by:

$$
\left[\Phi_{a b c}\right]=[L]\left[i_{a b c}\right]+\left[\Phi_{a b c}^{\prime}\right] ;[L]=\left[\begin{array}{ccc}
L_{s s} & M_{s} & M_{s} \\
M_{s} & L_{s s} & M_{s} \\
M_{s} & M_{s} & L_{s s}
\end{array}\right]
$$

$L_{s s}$ and $M_{s}$ representing the self-inductance and the mutual inductance between stator windings. $\Phi_{a b c}{ }^{\prime}$ is the rotor flux seen by the stator windings. It represents the amplitudes of the voltages induced in the stator phases without load.

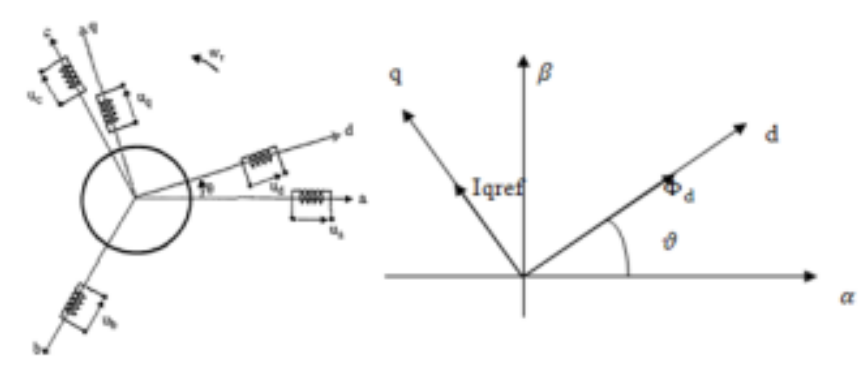

Figure 1. Diagram representing stator winding in abc and dq frames

Substituting (3) in (1):

$$
\left[V_{a b c}\right]=[R]\left[i_{a b c}\right]+[L] \frac{d\left[i_{a b c}\right]}{d t}+\left[\Phi_{a b c}^{\prime}\right]
$$

The electromagnetic torque is expressed by:

$$
T_{e}=\frac{1}{\omega_{r}}\left(\left[e_{a b c}\right]^{t}\right)\left(\left[i_{a b c}\right]\right)
$$

Where $e_{a b c}=\frac{d\left[\Phi_{a b c}\right]}{d t}$ represents the electromotive forces generated by the stator phases. $\omega_{r}$ Is rotation speed of the rotor in $[\mathrm{rad} / \mathrm{s}]$.

Note that the equation (4) leads to joined and highly non-linear equations. To simplify this problem, the majority of research in literature prefer to use the Park transformation which, by a transformation applied 
to real variables (voltages, currents and flux), provides fictive variables called dq components or Park's equations. Physically, this transformation is interpreted as a substitution for stationary windings (a,b,c) by rotating windings $(\mathrm{d}, \mathrm{q})$ which rotate with the rotor. This transformation makes the dynamic equations of $\mathrm{AC}$ motors simpler.

The Park transformation is defined as follows:

$$
\left[X_{d q o}\right]=\left[K_{\theta}\right]\left[X_{a b c}\right]
$$

Where $X$ may be a current, a voltage or a flux and $\theta$ is the rotor position. $X_{d q}$ represent longitudinal and transversal components of the stator variables (voltages, currents, fluxes and inductances).

The transformation matrix $K_{\theta}$ is given by [3]:

$$
\left[K_{\theta}\right]=\sqrt{\frac{2}{3}}\left(\begin{array}{ccc}
\frac{1}{\sqrt{2}} & \cos \theta & -\sin \theta \\
\frac{1}{\sqrt{2}} & \cos \left(\theta-\frac{2 \pi}{3}\right) & -\sin \left(\theta-\frac{2 \pi}{3}\right) \\
\frac{1}{\sqrt{2}} & \cos \left(\theta-\frac{4 \pi}{3}\right) & -\sin \left(\theta-\frac{4 \pi}{3}\right)
\end{array}\right)
$$

The inverse matrix

$$
\left[K_{\theta}\right]^{-1}=\left[K_{\theta}\right]^{t}=\sqrt{\frac{2}{3}}\left[\begin{array}{ccc}
\frac{1}{\sqrt{2}} & \frac{1}{\sqrt{2}} & \frac{1}{\sqrt{2}} \\
\cos \theta & \cos \left(\theta-\frac{2 \pi}{3}\right) & \cos \left(\theta-\frac{4 \pi}{3}\right) \\
-\sin \theta & -\sin \left(\theta-\frac{2 \pi}{3}\right) & -\sin \left(\theta-\frac{4 \pi}{3}\right)
\end{array}\right]
$$

Applying the transformation (6) to the system (1) we have the electrical equations in the dq reference:

$$
\begin{gathered}
V_{d}=R_{s} i_{s d}+\frac{d \Phi_{s d}}{d t}-\omega_{r} \Phi_{s q} \\
V_{q}=R_{s} i_{s q}+\frac{d \Phi_{s q}}{d t}+\omega_{r} \Phi_{s d}
\end{gathered}
$$

The flux equation:

$$
\begin{aligned}
& \Phi_{s d}=L_{s d} i_{s d}+\Phi_{f} \\
& \Phi_{s q}=L_{s q} i_{s q}
\end{aligned}
$$

$\Phi_{f}$ is the flux created by the magnets in the rotor.

By replacing (11) and (12) and in $V_{q}, V_{d}$ we obtain the following equations [9]:

$$
\begin{aligned}
& V_{d}=R_{s} i_{s d}+L_{s d} \frac{d i_{s d}}{d t}-\omega_{r} L_{s q} i_{s q} \\
& V_{q}=R_{s} i_{s q}+L_{s q} \frac{d i_{s q}}{d t}+\omega_{r}\left(L_{s d} i_{s d}+\Phi_{f}\right)
\end{aligned}
$$

Equations (13) and (14) form a second order differential equation system that models the electrical behavior of the synchronous permanent magnet [3] 

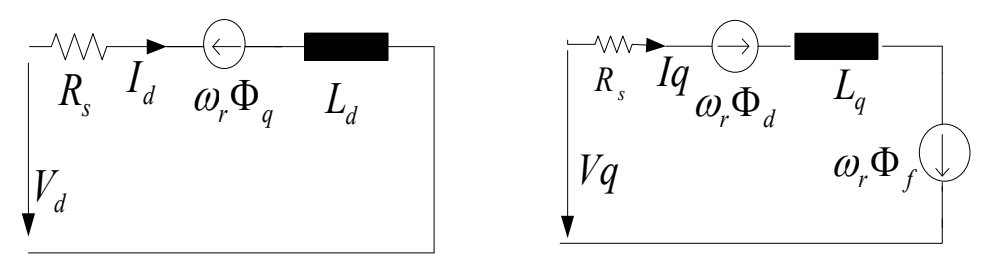

Figure 2. Equivalent circuit of a permanent magnet synchronous motor in the dq frame

The electromagnetic torque $\left(T_{e}\right)$ is produced by the interaction between the poles formed by the rotor magnets and the poles generated by the MMF (stator currents) in the gap.

$$
\begin{aligned}
& T_{e}=p\left(\Phi_{s d} i_{s q}-\Phi_{s q} i_{s d}\right) \\
& \text { Or } T_{e}=p\left[\Phi_{f} i_{q}+\left(L_{d}-L_{q}\right) i_{d} i_{q}\right]
\end{aligned}
$$

The equation of the mechanical torque is

$$
\begin{aligned}
& T_{e}=J \frac{d \omega_{m}}{d t}+T_{l}+B \omega_{m} \\
& J \frac{d \omega_{m}}{d t}=T_{e}-T_{l}-B \omega_{m} \text { and } \omega_{m}=\frac{\omega_{r}}{p}
\end{aligned}
$$

$\omega_{\mathrm{m}}$ and $\omega_{\mathrm{r}}$ represent the mechanical speed and the electrical speed respectively; with: $B, J, P$, and $T_{l}$ respectively define the damping coefficient, moment of inertia of the rotor and the number of pairs of poles and the load torque.

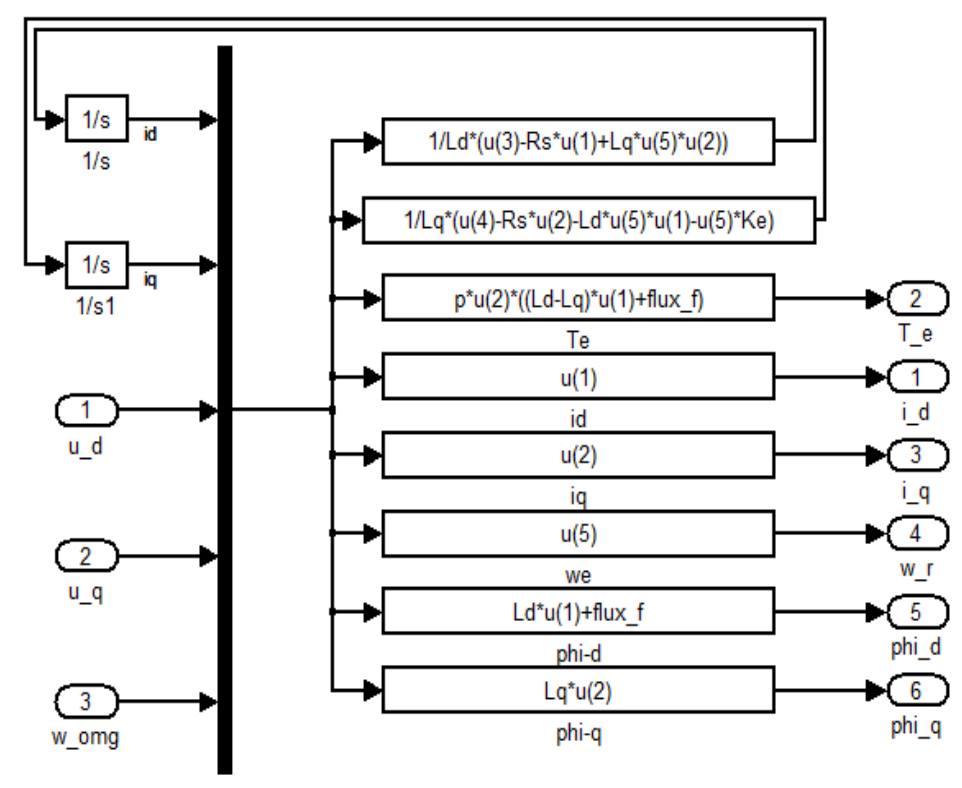

Figure 3. Implementation of PMSM in Simulink in dq frame

We can deduce the final form of PMSM equations in the dq frame 


$$
\begin{aligned}
& \frac{d i_{d s}}{d t}=-\frac{R_{s}}{L_{d}} i_{d s}+\frac{L_{q}}{L_{d}} \omega_{r} p i_{q s}+\frac{V_{d}}{L_{d}} \\
& \frac{d i_{q s}}{d t}=-\frac{R_{s}}{L_{q}} i_{q s}-\frac{L_{d}}{L_{q}} \omega_{r} p i_{d s}-\frac{\Phi_{f}}{L_{q}} \omega_{r} p+\frac{V_{q}}{L_{q}} \\
& \frac{d \omega_{r}}{d t}=\frac{p}{J}\left[\Phi_{f} i_{q s}+\left(L_{d}-L_{q}\right) i_{d s} i_{q s}\right]-\frac{1}{J} T_{L}-\frac{B}{J} \omega_{r}
\end{aligned}
$$

\section{FIELD ORIENTED CONTROL PRINCIPAL}

We can determine the reference torque to impose on the motor and the speed reference from the electromagnetic torque equation expressed in terms of Park's components shown in (16), if we impose the current $i_{\text {sd.ref }}=0$, the torque's formula will be: $T_{e}=p \Phi_{f} i_{s q}=k i_{s q}$

$$
\text { the current } \quad i_{s q r e f}=\frac{T_{e . r e f}}{p \Phi_{f}}
$$

To preserve the torque $T_{e}$ proportional to the current $\mathrm{i}_{\mathrm{sq}}$, we must control the angle $\alpha=\pi / 2$, and the angle $\alpha$ is determined by the following formula [3].

$$
\alpha=\operatorname{arctg}\left(\frac{i_{s q}}{i_{s d}}\right)
$$

\subsection{Inverter modeling}

The inverter transforms a DC voltage into an alternating voltage with a varying amplitude and frequency. Its bridge structure is composed mostly of electronic switches such as IGBTs, power transistors or thyristors. Its operating principle is based on controlled switching in a suitable manner (usually a pulse width modulation), the source is modulated to obtain a wanted AC signal frequency. Two types of inverters are used; the voltage inverter and the current inverter.

The voltage inverter with six switches, supplied by the photovoltaic generator and operating in pulse-width modulation (PWM) is commonly used for this application [3].

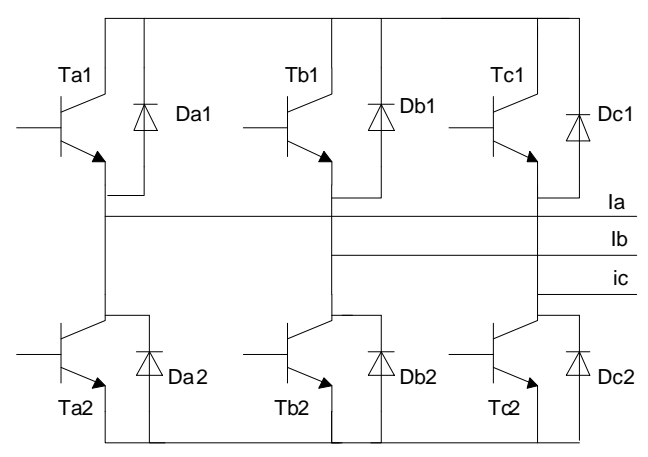

Figure 4. The voltage inverter with six switches

We have immediately the following relations at the load (balanced system)

$$
i_{a}+i_{b}+i_{c}=0 \quad ; \quad v_{a}+v_{b}+v_{c}=0
$$

Complex voltage functions: 


$$
\left\{\begin{array}{l}
u_{a b}=v_{a o}-v_{b o} \\
u_{b c}=v_{b o}-v_{c o} \\
u_{c a}=v_{c o}-v_{a o}
\end{array}\right.
$$

by making the difference member to member we obtain

$$
u_{a b}-u_{c a}=2 v_{a o}-v_{b o}-v_{c o}=3 v_{a}
$$

Therefore

$$
\begin{aligned}
& v_{a}=\frac{1}{3}\left(2 v_{a o}-v_{b o}-v_{c o}\right) \\
& v_{b}=\frac{1}{3}\left(2 v_{b o}-v_{a o}-v_{c o}\right) \\
& v_{c}=\frac{1}{3}\left(2 v_{c o}-v_{b o}-v_{a o}\right)
\end{aligned}
$$

The control variables act upon the controllable switches, we can define the following switching function to set the state of the switches.

The voltage of the inverter branch relative to the negative pole of the DC bus is:

$$
\left(\begin{array}{l}
v_{a} \\
v_{b} \\
v_{c}
\end{array}\right)=\frac{V_{D C}}{3}\left(\begin{array}{ccc}
2 & -1 & -1 \\
-1 & 2 & -1 \\
-1 & -1 & 2
\end{array}\right)\left(\begin{array}{l}
d_{a} \\
d_{b} \\
d_{c}
\end{array}\right)
$$

\subsection{The hysteresis current control technique}

It is a simple technique directly interested in current control; it limits the maximum current and is less sensitive to load variations. this method is used to control the current of a voltage inverter in such to force the phase currents of the motor to follow a sinusoidal reference current calculated from the currents (isdref, isqref) and from the rotor position $\varphi$. if the error, which is the difference between the reference current of a phase and the same phase current, reached the upper limit $\left(i_{\text {ref }}+\Delta I\right)$ the switch arm of the inverter corresponding to the same phase is started and connected to the $(-)$ pole of the power source to reduce the current while, if the error reached the lower limit $\left(i_{r e f}-\Delta I\right)$ the switch connected to the $(+)$ terminal of the power source should be started to increase the flow of the corresponding phase.

The lower and upper limits of the hysteresis band $\Delta \mathrm{I}$ are set by the motor absorbed current and the maximum switching frequency of switches respectively.

A narrow band of hysteresis implies a current more similar to the sine wave with a low harmonic content, and a switching frequency higher and higher, and vice versa.

The current references are given by [4]

$$
I=\left(\begin{array}{c}
i_{a . r e f} \\
i_{b . r e f} \\
i_{c . r e f}
\end{array}\right)=\frac{T_{e . r e f}}{p \Phi_{f}}\left(\begin{array}{c}
\cos \left(\theta+\frac{\pi}{2}\right) \\
\cos \left(\theta+\frac{\pi}{2}-\frac{2 \pi}{3}\right) \\
\cos \left(\theta+\frac{\pi}{2}-\frac{4 \pi}{3}\right)
\end{array}\right)
$$

These currents are sinusoidal functions of rotor position. They create in the gap a field with magnetic axis in quadrature with the axis of the magnets' field. They are in phase with the electromotive forces induced in these windings by the magnets.

When the reference current in a phase deviates from its reference, each controller requires switching the switches of each inverter arm and keeps it within the hysteresis band $\boldsymbol{\Delta I}[3]$. 


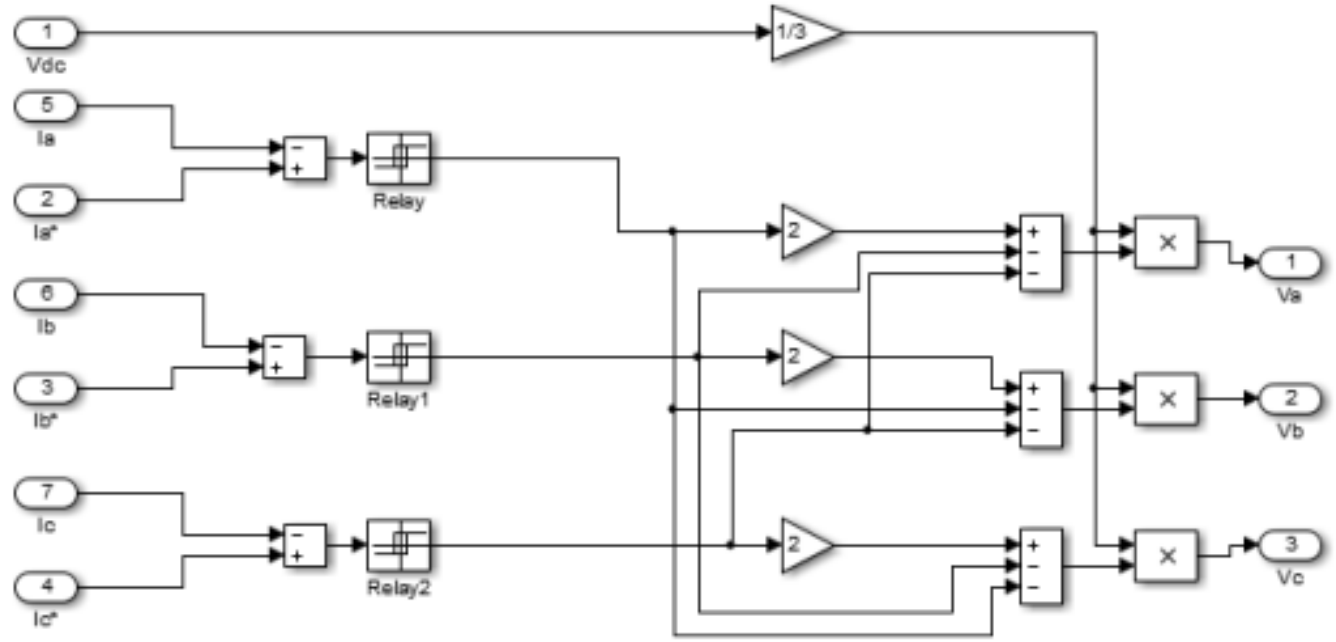

Figure 5. Representation of hysteresis current control

\section{MODELING OF THE PHOTOVOLTAIC CELL}

The photovoltaic generator which produces a continuous electrical current is represented by a standard model with a single diode, established by Shockley for a single PV cell and generalized to a PV module by considering it as a set of identical cells connected in series-parallel [5],[6].

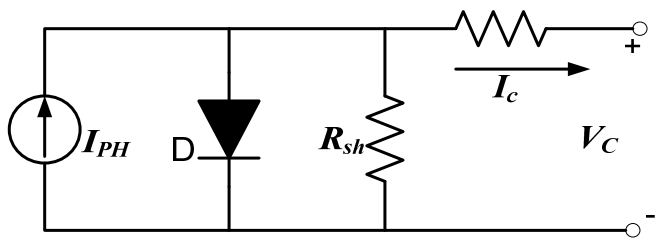

Figure 6. One diode equivalent circuit model of PV cell

$$
I_{C}=I_{p h}-I_{0}\left(\exp \left(\frac{q\left(V_{C}+R_{S} I_{C}\right)}{n k T_{C}}\right)-1\right)-\frac{\left(V_{C}+R_{S} I_{C}\right)}{R_{S h}}
$$

$I_{p h}$ Photocurrent [A]

$I_{0} \quad$ Saturation current $[\mathrm{A}]$

$q$ Electron charge: $1.602 .10^{-19}$ coulomb

$k$ Boltzmann's constant $: 1.381 .10^{-23} \mathrm{~J} / \mathrm{K}$.

$\mathrm{n}$ Ideality factor, varies from 1 to 2 as follows:

The current source depends mainly on radiation and operating cell temperature, which is described

$$
I_{P H}=\frac{G}{G_{r e f}}\left[I_{s c}+\mu_{I, S C}\left(T_{c}-T_{c, r e f}\right)\right]
$$

While $I_{s c}$ represents cell short circuit current at $25^{\circ} \mathrm{C}$ and $1000 \mathrm{~W} / \mathrm{m}^{2}$

$\mu_{I, S C}$ Short circuit cell temperature coefficient $T_{c \text { ref }}$ is the cell reference temperature and $G$ is the solar radiation in $\mathrm{W} / \mathrm{m}^{2}$, on the other hand the saturation current varies with cell temperature, it is described as follows: 
$I_{0}=I_{0, r e f}\left(\frac{T_{c}}{T_{c, r e f}}\right)^{3} \exp \left[\frac{q e_{g a p}}{n k}\left(\frac{1}{T_{c, r e f}}-\frac{1}{T_{c}}\right)\right]$

$I_{0, \text { ref }}$ reverse saturation current at the reference temperature. the width of the band gap $e_{\text {gap }}$ for the semiconductor material, for silicon equal to $1.11 \mathrm{eV}$.

The temperature of the cell is calculated by:

$$
T_{c}=T_{a}+\frac{G}{800}(N O C T-20)
$$

$T_{a}$ Ambient temperature ${ }^{\circ} \mathrm{C}$.

NOCT Nominal operation cell temperature in ${ }^{\circ} \mathrm{C}$

Where, $I_{P H}\left(G_{r e f}\right)$ is known under the standard conditions of $G_{r e f}=1000 \mathrm{~W} / \mathrm{m}^{2}(1$ sun) at spectral distribution of AM 1.5 and cell temperature of $25^{\circ} \mathrm{C}$ or as otherwise specified (on curves) From the manufactures catalogues of a typical silicon monocrystalline PV cell SOLAREX MSX-83, the value of Short-circuit current $I_{P H}\left(G_{r e f}\right)=I_{S C}=5.27 \mathrm{~A}$ and Open-circuit voltage $V_{O C}=21.2 \mathrm{~V}$

MSX83 Solarex module, typical of $83 \mathrm{~W}$, polycrystalline was chosen to model the photovoltaic generator, the module contains 36 cells connected in series. Modeling of the PV module is made by Matlab software.
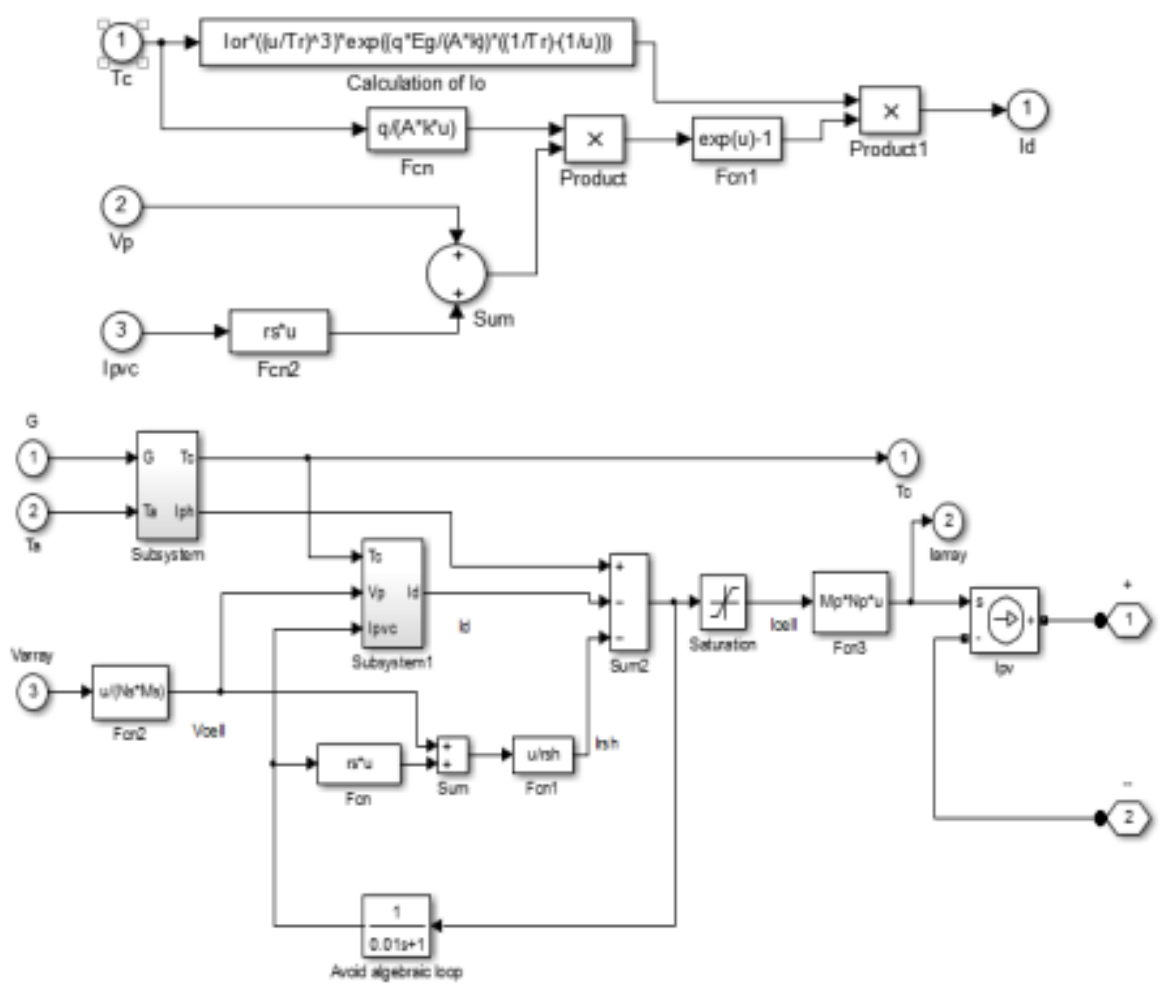

Figure 7. Implementation of PV in Matlab / Simulink

\section{SIZING OF PHOTOVOLTAIC MODULES}

The following equation determines the maximum number of PV modules in series

$$
N_{s}=\frac{U_{\max }}{U_{c o} \times 1.15}
$$


$N_{\mathrm{S}}$ : maximum number of PV modules in series

$U_{\text {max }}$ : Maximum acceptable input voltage

$U_{\text {co }}$ : open circuit voltage of a module

1.15: safety factor required by the standard UTE C15-712

The maximum number of photovoltaic strings in parallel is calculated by the following formula:

$$
N_{p}=\frac{I_{\max }}{I_{c c} \times 1.25}
$$

$I_{\text {cc }}$ : short-circuit current of photovoltaic modules

$I_{\max }$ : maximum power acceptable by the inverter

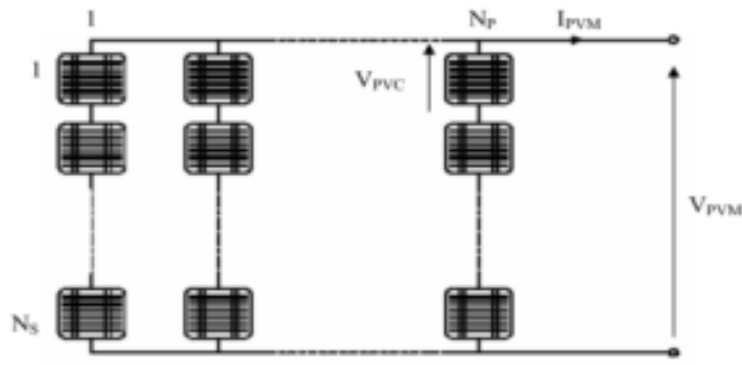

Figure 8. Configurations of PV array

The connection between dc link power and into power rotating $d q$ frame can be expressed as

$$
P_{d c}=V_{d c} I_{d c}=\left(V_{s d} I_{s d}+V_{s q} I_{s q}\right)
$$

The modules in a PV system are usually connected in arrays. Figure 8 illustrates the case of an array with $M_{P}$ parallel branches each with $M_{S}$ modules in series.

The equation for a PV module can be expressed using the one-diode PV cell model as follows $N s$ number of cells in series and $N_{p}$ number of cells parallel. [5]

$$
\begin{aligned}
& V_{P V M}=N_{S} V_{P V C} \\
& I_{P V M}=N_{P} I_{P V C}
\end{aligned}
$$

Where $M$ designates a PV module and $C$ designate a PV cell. PV modules are coupled together form a PV array. The equation for a PV array can be expressed by adapting the PV module's equation as follows:

$$
\begin{gathered}
V_{P V A}=M_{S} N_{S} V_{P V C} \\
I_{P V A}=M_{P} N_{P} I_{P V C}
\end{gathered}
$$

The number of PV array contains 36 modules with a total peak power. PV modules are collected in sizes using 18 modules in series and 2 modules in parallel. 


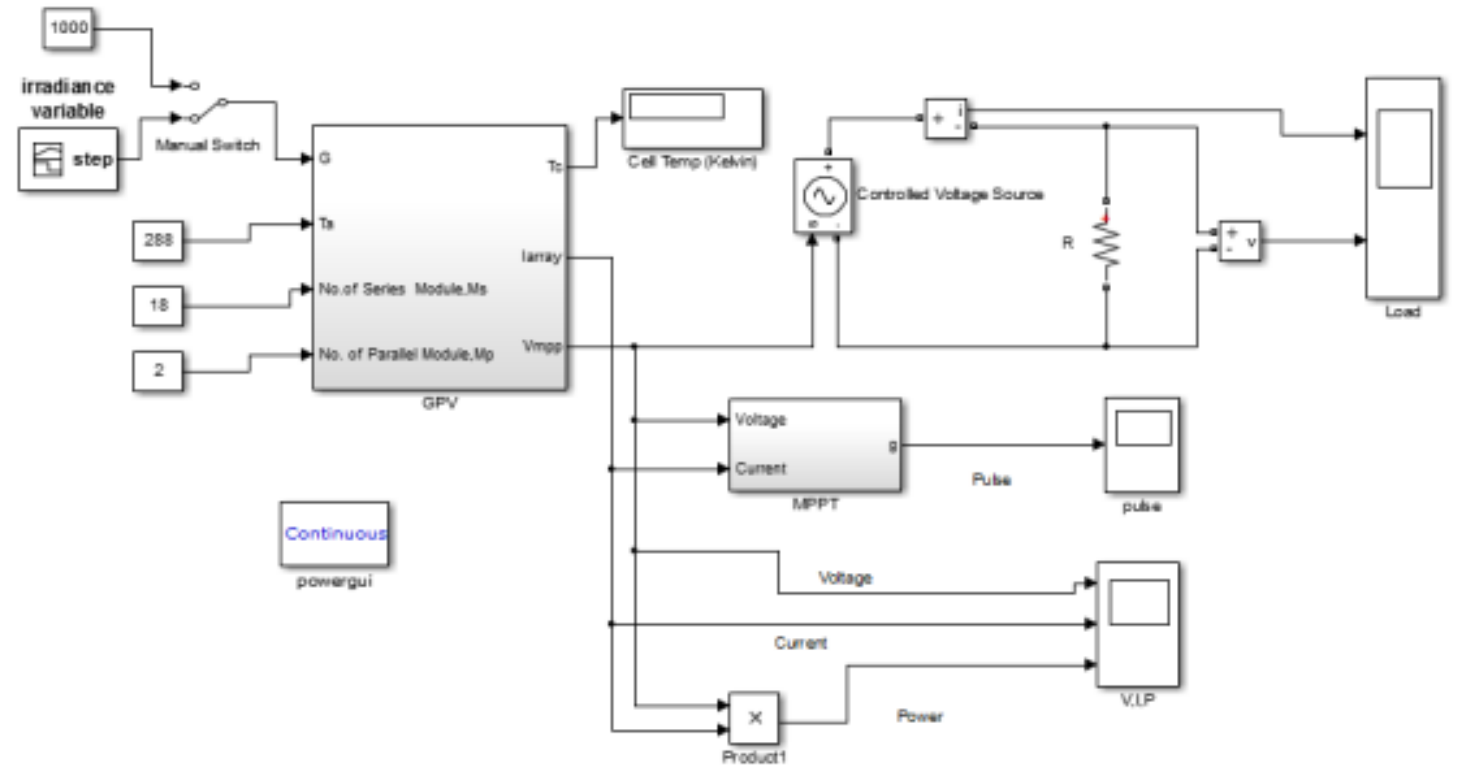

Figure 9. Implementation the PVarray
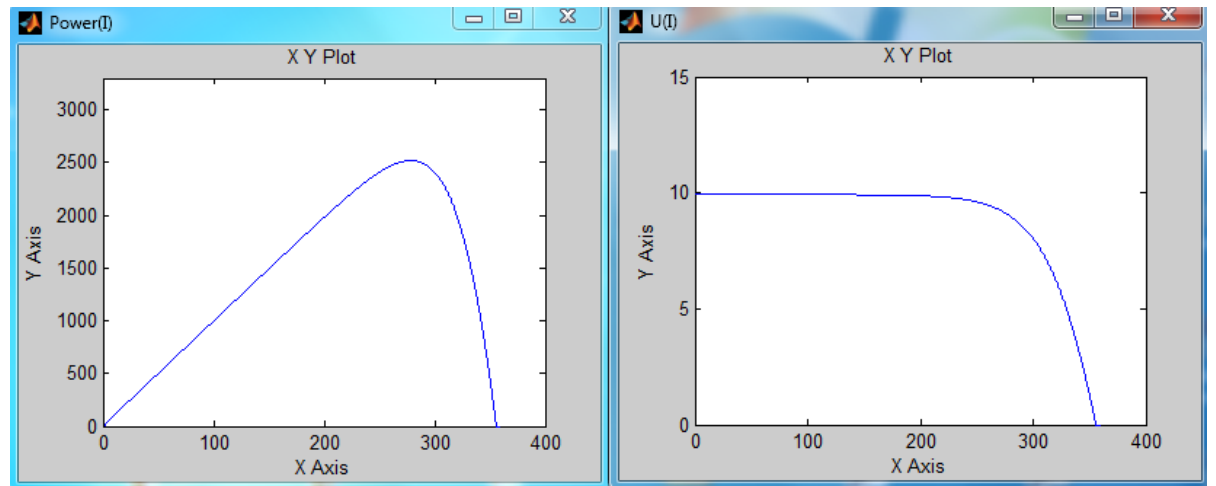

Figure 10. Characteristic Power (I) and $\mathrm{U}(\mathrm{I})$ for $\mathrm{Ns}=36, \mathrm{~Np}=1, \mathrm{Ms}=18, \mathrm{Mp}=2$

\section{BOOST CONVERTER}

Figure 11 presents a schematic of a DC/DC boost converter it is build by power components and passive components, $R, L$ and $C$. The main task of the boost converter is regulating the voltage of the photovoltaic generator, to get maximum power; through control of the duty cycle $D$. it is used as an interface between the PV generator and the inverter. A Boost converter increases the voltage provided by the photovoltaic cell, thereby reducing the number of cells required to reach the desired voltage level.

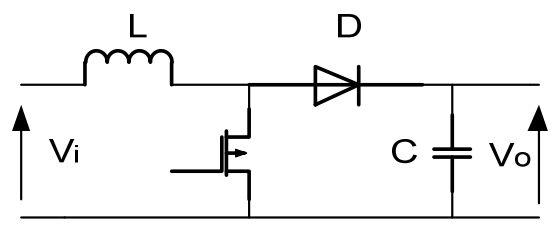

Figure 11. Converter boost dc/ dc

The electrical equations of boost converter in Continuous Conduction Mode can be written: 
$L \frac{d I_{L}}{d t}=V_{i}-(1-D) V_{o}$

$C \frac{d V_{o}}{d t}=(1-D) I_{L}-\frac{V_{o}}{R}$

The computation of the components $L$ and $C$ is made by the expressions following Minimum Inductor size

$$
L>\frac{V_{i} D(1-D)}{2 f I_{o}}
$$

Minimum capacitor

$$
C>\frac{D I_{o}}{\Delta V f}
$$

$\Delta V \quad$ Maximum admissible voltage ripple

$I_{o} \quad$ Output current

$f \quad$ switch frequency

7.

T ALGORITHM INCREMENTAL CONDUCTANCE

MPP

This method uses the incremental conductance, Voltages and currents of the panel are measured, so that the controller can calculate the conductance and the incremental conductance and determine its behavior. Conductance is defined by $G=\frac{I}{V}$ and the incremental by ${ }_{G}=\frac{\Delta I}{\Delta V}$ finally, deriving the power versus to the voltage obtained: $\quad \frac{1}{V} \frac{d P}{d V}=G+\Delta G$

We need only to look for the conductance which, according to the value of three cases to consider

$$
\begin{array}{cc}
\Delta G=-G & (d P / d V=0) \\
\Delta G>-G & (d P / d V>0) \\
\Delta G<-G & (d P / d V<0)
\end{array}
$$

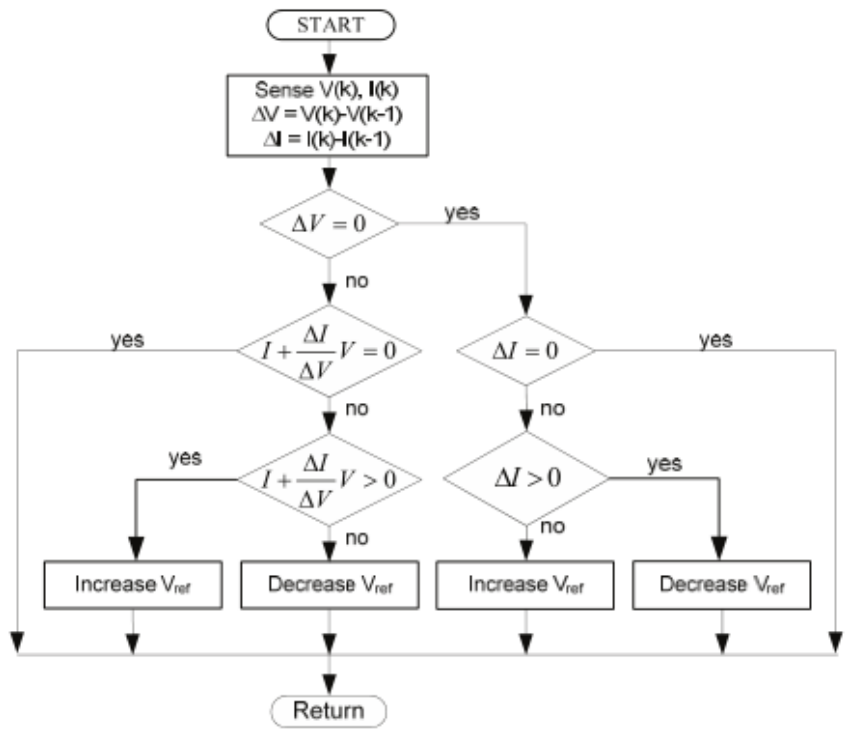

Figure 12. IncCond algorithm 


\section{SPEED CONTROLLER DESIGN}

The design of the speed controller is important from the point of view of imparting desired transient and steady state characteristics to speed controlled PMSM drive system. A PI controller is adequate in industry.

Selection of the gain and time constant of such a controller by using the Bode criteria is simple if the $\mathrm{d}$ axis stator current is assumed to be zero. [1],[7].

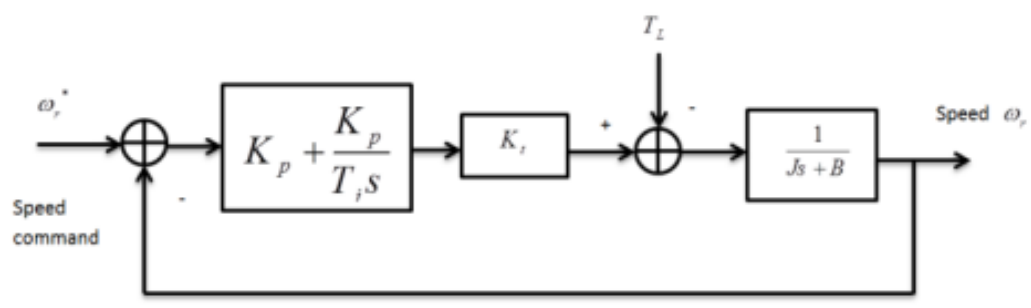

Figure 13. Bloc diagram of a speed controller PI of PMSM drive

A proportional plus integral (PI) controller is used to process the speed error between the speed reference and filtered speed feedback signals, the transfer function of the speed controller is given as:

$$
G_{s}(S)=K_{p}+\frac{K_{p}}{T_{i} S}
$$

$K_{p}$ is speed loop proportional gain and that $T_{i}$ is the integral time constant

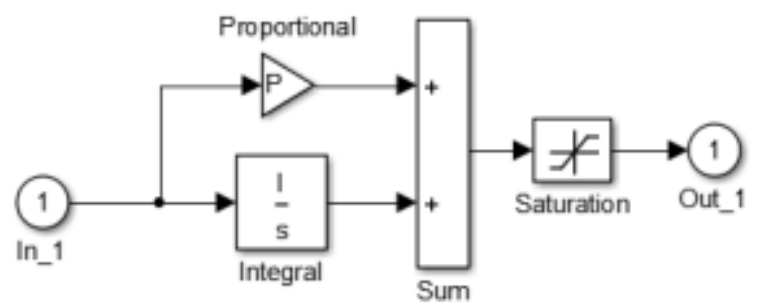

Figure 14. Implantation the speed controller with saturation in Simulink

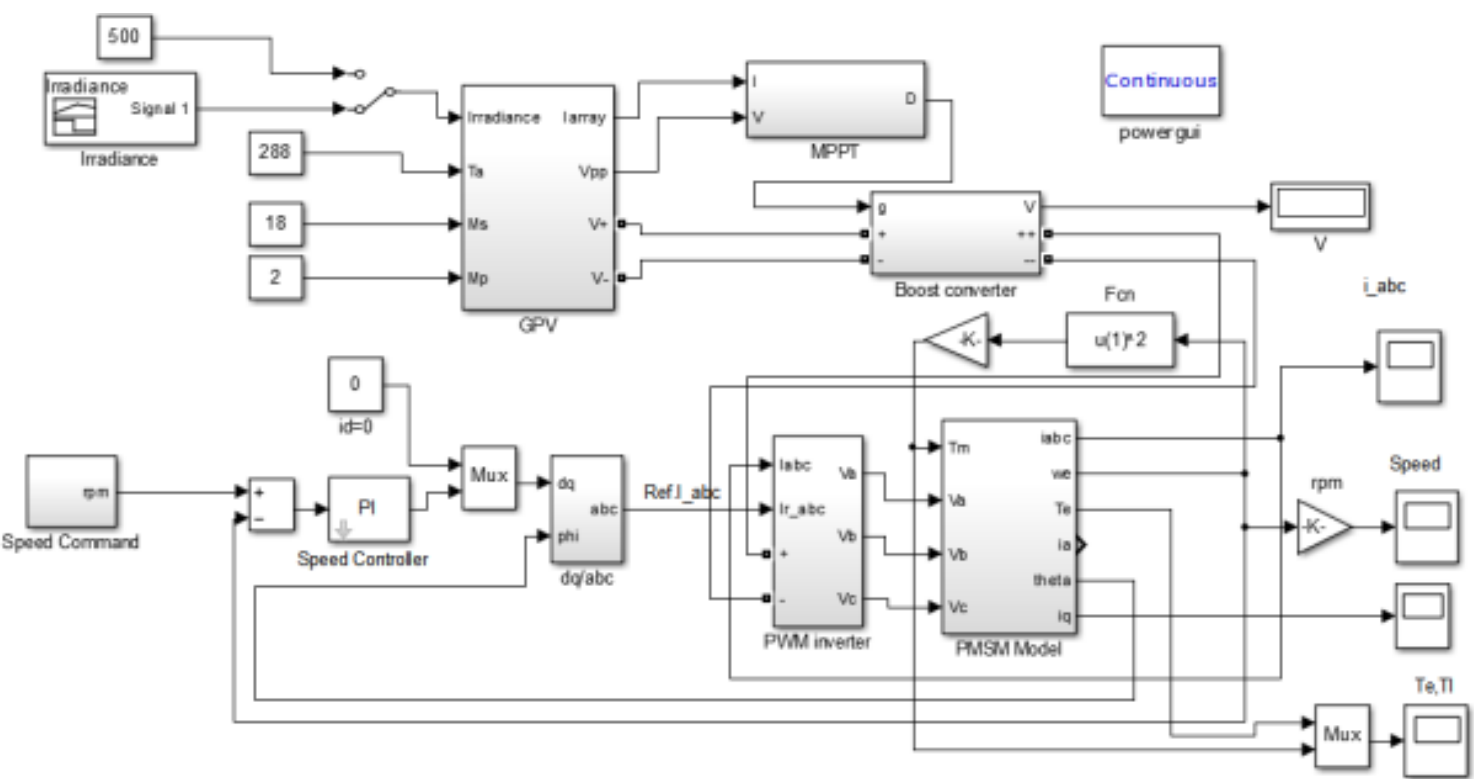

Figure 15. Overall vectorial command system of a PMSM motor fed by a photovoltaic generator 


\section{RESULTS AND ANALYSIS}

We have tested our system using a load where the torque increases with the speed squared such pump centrifugal and fan etc.

$$
T_{\text {load }}=K \Omega^{2}
$$

Where $K$ is the constant.

The system established in Simulink for a drive system of PMSM with reference current hysteresis control method.

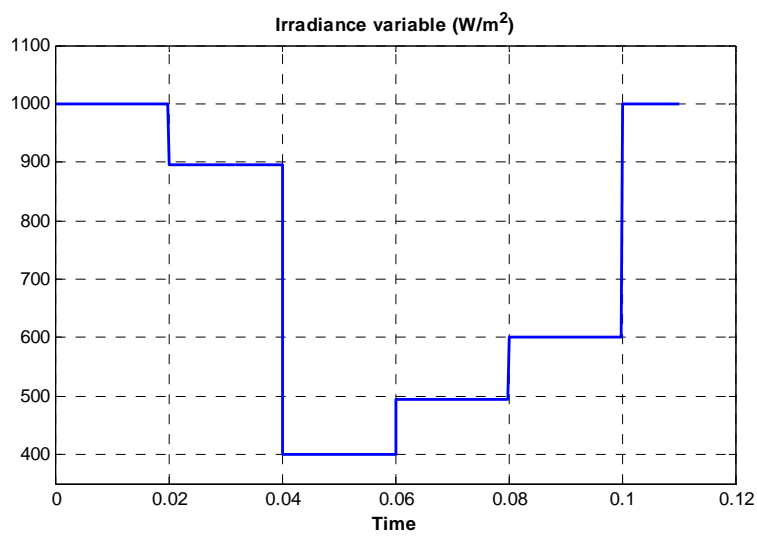

Figure 16. forme for variable irradiance

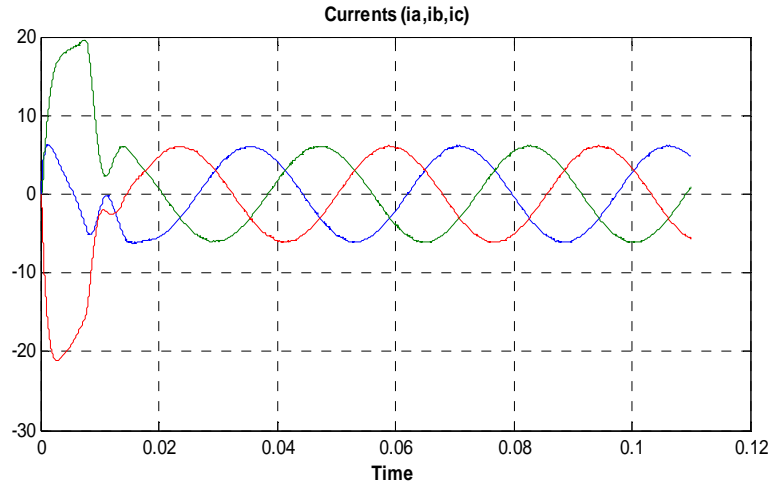

Figure. 17. Diagram of $I_{a b c}$ versus time

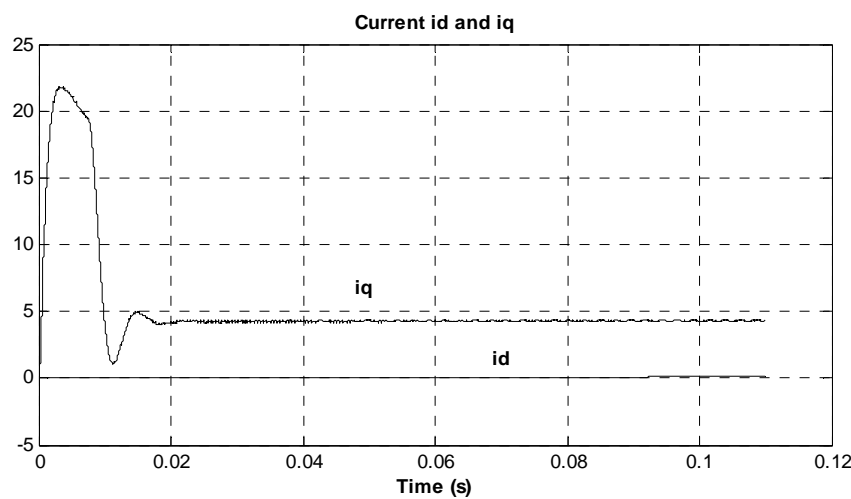

Figure. 18. Diagram of id and iq versus time 


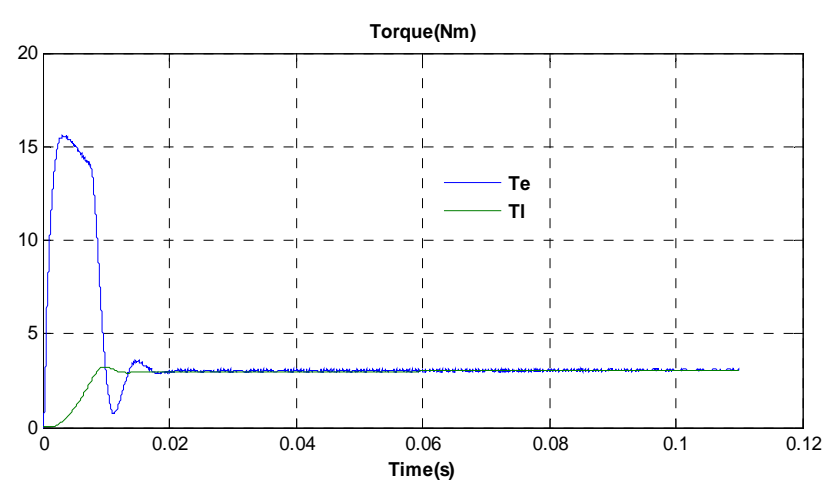

Figure. 19. Diagram of the torque versus time

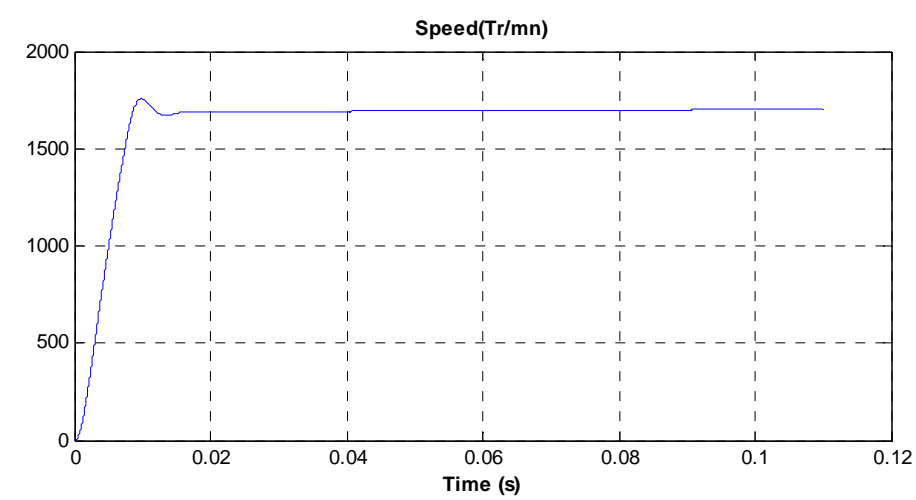

Figure. 20. Diagram of rotor speed versus time

Figure 17 shows phase currents of the synchronous motor with permanent magnet. It is clear that the currents are not sinusoidal at startup and becomes sinusoidal when the motor reaches the steady state. The motor absorbs a high current at start-up. $i_{d q}$ currents increase when the motor is controlled by oriented flux, the current $i_{d}$ is zero $\left(i_{d}=0\right)$, while $i_{q}$ current increases at start up then stabilizes in steady state.

The torque $T_{e}$ developed by the motor follows the instructions properly; its value at startup is five times the value of the rated torque. The electromagnetic torque $T_{e}$ becomes equal to the load torque $T_{l}$ during $2 \mathrm{~ms}$. Figure 20 shows speed variation versus time. Steady speed is the same as that of equals the commanded speed reference (1800 tr/mn).

Simulink program of Matlab is used for simulation, The PMSM parameters used in the tests are as follows: stator Resistance $R_{s}=1.4 \Omega$, stator inductance $L_{d}=L_{q}=0.006$ Henry, Magnet flux linkage, $\Phi_{f=} 0.17 \mathrm{~Wb}$ System inertia $J=0.00176 \mathrm{~kg} \mathrm{~m}$, viscous friction coefficient $B=0.00038818 \mathrm{~N} . \mathrm{s} / \mathrm{rad}$, rated electrical speed $\omega_{\mathrm{n}}=1800 \mathrm{tr} / \mathrm{mn}$, pole pairs $n p=3$. The currents are filtered by a three-order low pass filter with passband edge frequency equal to $12566 \mathrm{rad} / \mathrm{s}$ [8],[9].

\section{CONCLUSION}

The vector control is introduced in order to control the permanent magnet synchronous machine with maximum power. It is based on a transient model. It allows precise adjustment of the machine torque and can ensure torque at zero speed.

In this paper, we have presented the field oriented control principle of the permanent magnet synchronous motor, fed by a PV Array generator in the presence of a speed loop with a PI corrector. We can conclude that the field oriented control has a good dynamic and static torque and flux results.

In spite of the variablity of the radiation (Figure 19) and the temperature in the day, using MPPT with the PV generator gives currents and voltages with the most sinusoidal form. 


\section{REFERENCES}

[1] R. Mathew and D. Houghton, "Vector control techniques for induction motors," Wardina Oghanna Centre for Railway Engineering, Central Queensland University, Rockhampton. Q 4702 Australia.

[2] J. C. Balda and P. Pillay, "Speed controller design for a vector-controlled permanent magnet synchronous motor drive with parameter variations," Industry Applications Society Annual Meeting, Conference Record of the 1990 IEEE Magnet Synchronous Motor, 1990.

[3] L. Prokop and P. Grasblum, "3-Phase PM Synchronous Motor Vector Control Using a 56F80x, 56F8100, or56F8300 Device ( AN1931)”.

[4] "For Robot Axis," Proceedings of the 13th WSEAS International Conference on SYSTEMS.

[5] J. A. Gow and C. D. Manning, "Development of a Photovoltaic Array Model for Use in Power-Electronics Simulation Studies," IEE Proceedings of Electric Power Applications, vol/issue: 146(2), pp. 193-200, 1999.

[6] H. Tsai, et al., "Development of generalized photovoltaic model using MATLAB/SIMULINK," Proceedings of the World Congress on Engineering and Computer Science 2008 WCECS, October 22 - 24, 2008, San Francisco, USA.

[7] Y. S. Kim, et al., "MRAS Based Sensorless Control of Permanent Synchronous Motor,".

[8] P. Borsje, et al., "A Comparative Study of Kalman Filtering for Sensorless Control of a Permanent-Magnet Synchronous Motor Drive," Department of EE, The Hong Kong Polytechnic University Hong Kong, China.

[9] A. Bara, et al., "DSP Application on PMSM Drive Control,". 